\title{
Citizens' attitudes and perceptions towards genetically modified food in Chile: Special emphasis in CRISPR technology
}

\author{
Tamara Tadicha, Sebastián Escobar-Aguirre ${ }^{\mathrm{b} *}$
}

\begin{abstract}
To date, there has been an increase in genome modification biotechnologies that improve production and food security but the process has not been accompanied by the delivery of information about them intended for citizens. This is essential considering that to achieve better health, food security and sustainability these biotechnologies need to be incorporated into production systems. This study aimed to explore perceptions and attitudes of Chilean citizens towards the use of genome modifications with an emphasis on transgenes and genome editing (CRISPR). An electronic questionnaire was applied, and afterwards the results were analysed through descriptive statistics, GLM, Spearman's correlation and Wilcoxon Signed Rank test. A total of 702 questionnaires were analysed. High awareness of concepts such as transgenic and cloning was reported with CRISPR being the least known term. Most respondents perceived negative effects on health regarding the consumption of genetically modified products, with women having a significantly more negative attitude. Still, a high willingness to use CRISPR for improving animal and human health was reported. When comparing vegetable and animal products that underwent CRISPR or transgenes, the willingness to consume these products was higher for vegetables. The results show that changes in perception can be achieved after providing the definition of CRISPR and transgenic, therefore, consumer education seems to be essential. Science communication focused on making information about genome modification biotechnologies available to citizens could promote more positive attitudes and perceptions and facilitate their future implementation in the country.

Key words: attitudes, CRISPR, genetically modified food, perceptions.
\end{abstract}

\section{INTRODUCTION}

Genetic modification (GM) allows novel traits to be introduced in the agricultural sector in organisms such as fish, livestock, poultry and crops to improve their productivity. Historically, the introduction of the first genetically modified food into the US market began in 1996 with GM maize (Cui and Shoemaker 2018). Since then, new genetic approaches are being continuously developed and implemented in the food chain, promising more efficient production and better quality for consumers (Dong and Ronald 2019). These technologies (GM) allow enhanced nutritional value (i.e. biofortified crop), economic, and agronomic benefits (i.e. lower use of pesticides) among others (Dong and Ronald 2019). However, the estimated increase in global population - 10 billion people by 2050 - has provoked an enormous pressure on food supply, which is amplified by the limitation of arable land, global warming effects and limited water resources (Cui and Shoemaker 2018). In a recent review by Menchaca (2021), emphasis is given to the challenge of increasing productivity while conserving the environment and biodiversity. In this context, new alternatives and disruptive technologies need to be implemented to ensure food security and sustainability of food production systems. Among these, the advent of

Received: 11.05.2021.

Accepted: 16.08.2021.

${ }^{a}$ Instituto de Ciencia Animal, Facultad de Ciencias Veterinarias, Universidad Austral de Chile, Valdivia, Chile.

bepartamento de Ciencias Animales, Facultad de Agronomía e Ingeniería Forestal, Pontificia Universidad Católica de Chile, Santiago, Chile.

*Corresponding author: sebastian.escobar@uc.cl clustered regularly interspaced short palindromic repeats (CRISPR) has proved to be a powerful and precise tool for editing specific regions of plant and animal genomes (Bartkowski et al 2018, McFarlane et al 2019). Contrary to transgenics, this new mechanism can create precise incisions, mutations and substitutions in the genome of plant and animal cells with no new foreign DNA being added.

Nowadays, the CRISPR/Cas system has been successfully applied for genome editing in soybean (Jacobs et al 2015, Li et al 2015), maize (Svitashev et al 2016), tobacco, lettuce, rice (Woo et al 2015), and animals, including chicken (Véron et al 2015), rabbits (Kawano and Honda 2017), pigs (Hai et al 2014, Whitworth et al 2014), goats (Ni 2014), sheep (Crispo et al 2015), cattle (Gao et al 2017) and later to fish (Li et al 2021). Therefore, the development of GM foods (livestock species and crops) using CRISPR is one of the most realistic solutions considering the current global scenario. However, the debate for creating new genetically modified organisms (GMOs) is a permanent cause of concern among people and potential consumers (Schnettler et al 2008, 2012, 2016, Zhang et al 2016, Popek and Halagarda 2017, Bruetschy 2019).

In general terms, the debates over GM foods are focused on public awareness about the potential adverse effects on human health and the environment (Cui and Shoemaker 2018, Hanssen et al 2018). This uncertainty can be explained by deficient and ambiguous science communication strategy to the public; ethical and moral perceptions, and trust in governments and scientists (Shew et al 2018), all of which ends having an impact on perceptions and attitudes. Perceptions can be understood as the way a person interprets stimuli into something meaningful, although this interpretation can be substantially different from reality, 
while attitudes are a mental state of readiness towards something, it depends on perception and will influence decision making and guide behaviours (Pickens 2005). Previous work has shown public opposition to GMOs, probably the most studied case was the "GM Nation?" public engagement exercise that has been described as a "mess" (Tait 2001). This opposition has also been described in China where negative perceptions have been reported in $46.7 \%$ of surveyed people (Cui and Shoemaker 2018) and among the Dutch population approval is only around $30 \%$ (Hanssen et al 2018). However, and contrary to the negative perception of GMO food, the medical applications of GM were endorsed by $70 \%$ in the same report in Germany (Hanssen et al 2018). The perceived benefits and risks of GM are the main reason for certain attitudes towards genetic manipulation. For example, animal health and welfare can affect positively attitudes toward genome modifications in dairy cows in Canada (Ritter et al 2019), a similar conclusion was observed in a Japanese survey but related to genetic disease in humans and the use of gene therapy (Uchiyama et al 2018). In Chile, poor knowledge of the meaning of transgenic and a negative perception of animal production technologies has been reported before (Schnettler et al 2012, 2016), with a lower acceptance of food including beef or milk obtained through genetic modification and cloning. Nevertheless, the perceptions of Chilean citizens about CRISPR have not been studied.

In some countries, such as Canada, CRISPR is not subject to the conventional regulations of a genetically modified organism because no foreign DNA is added. It is important to open this local discussion to establish a new frame of science-policy implementation in genome editing, especially in Chile where it has not been determined the regulatory status of gene editing in animals yet.

With this in mind, this study aimed to explore, for the first time in Chile, the perceptions and attitudes of citizens towards genetically modified products with special emphasis on transgenes and genome editing in the agriculture and animal farming industries.

\section{MATERIAL AND METHODS}

To assess attitudes and perceptions towards genome modification biotechnologies a questionnaire was constructed in Spanish using the Google Forms tool (Google ® California, USA). The questionnaire consisted of five sections and accepted only one response per user, respondents had to be over 18 years old. Section one included the informed consent, then participants were asked about their demographic information (gender, age, region of residence, diet and education level). Section two contained general closed-ended questions about knowledge of different genetic modification tools and perceptions about their use. Section three focused on transgenic products, the definition of transgenic was provided and then seven closed-ended questions about their attitudes towards some vegetable and animal transgenic products. The fourth section on genome editing was included with the same seven questions provided in section three. Finally, section five consisted of one open-ended question where participants were asked to name genetically modified products of vegetable or animal origin that they perceive are present in the Chilean market.

The sample size was determined a priori assuming $95 \%$ power at an alpha of 0.05 . The data from the last national demographic survey ${ }^{1}$ (INE 2017) was used for the total number of households in Chile; a sample size of 385 surveys was estimated. Survey participants were recruited through social media such as Facebook, Instagram, Whatsapp (Facebook Inc., Menlo Park, CA, USA) and Twitter (Twitter Inc., San Francisco, CA, USA). The questionnaire was open between April and May of 2020. After closing the form, data was downloaded into an Excel spreadsheet and frequencies, means, standard deviations, and percentages were calculated. To evaluate the effect of demographic variables on perceptions a GLM was used, correlations were assessed using Spearman's correlation and Wilcoxon Signed Rank test was used to evaluate differences in perception of transgenes and genome edited products before and after providing the definitions. A $P$-value lower or equal to 0.05 was used to establish the significance of the results, the statistical software Minitab ${ }^{\circledR}$ 19 (PA, USA) was used. For the open-ended question, a frequency analysis was used.

\section{RESULTS}

A total of 709 respondents agreed to answer the questionnaire, from these 702 were included in the analysis and 7 were eliminated due to incomplete questionnaires or declaring ages below 18 years. The demographic characteristics are described in table 1. A similar percentage of responses was retrieved from females and males, with most participants being in the age range between 18 and 40 years of age. Most respondents had completed a technical or professional career, had an omnivore diet and were from the Province of Santiago in the Metropolitan region (table 1). Figure 1 shows that the most known tool for genetic modification was transgenes (97.4\%), while the least known one was CRISPR (33.8\%).

\section{PERCEPTIONS PRIOR TO DELIVERY OF BIOTECHNOLOGIES} DEFINITIONS

When asked about the possible negative effects of genetic modification tools on other animals or vegetables $64.8 \%$ perceived they do have a negative effect, $9 \%$ that they do not, $23.8 \%$ perceived that maybe and $2.4 \%$ do not know.

1 INE, Instituto Nacional de Estadísticas. 2017. https://www.ine.cl/ ine-ciudadano/definiciones-estadisticas/censo\#: :text=Resultados\%20 definitivos\%20CENSO\%202017,51\%2C1\%25)\%2C\%20mujeres. 
Table 1. Number and percentage of respondents according to socio-demographic characteristics $(n=702)$.

\begin{tabular}{|c|c|c|}
\hline & Number & Percentage \\
\hline \multicolumn{3}{|l|}{ Gender } \\
\hline Female & 344 & 49.0 \\
\hline Male & 346 & 49.3 \\
\hline Non-binary & 12 & 1.7 \\
\hline \multicolumn{3}{|l|}{ Age } \\
\hline $18-40$ & 376 & 53.6 \\
\hline 41 to 60 & 213 & 30.3 \\
\hline$>60$ & 113 & 16.1 \\
\hline \multicolumn{3}{|l|}{ Education } \\
\hline Did not complete high school? & 0 & 0 \\
\hline Completed high school? & 52 & 7.4 \\
\hline $\begin{array}{l}\text { Completed a technical or } \\
\text { professional degree? }\end{array}$ & 413 & 58.8 \\
\hline Completed a postgraduate degree? & 237 & 33.8 \\
\hline \multicolumn{3}{|l|}{ Diet } \\
\hline Omnivore & 599 & 85.3 \\
\hline Vegetarian & 82 & 11.7 \\
\hline Vegan & 21 & 3.0 \\
\hline \multicolumn{3}{|l|}{ Macrozone of residence* } \\
\hline North & 18 & 2.6 \\
\hline Center-North & 70 & 10.0 \\
\hline Metropolitan & 451 & 64.2 \\
\hline Center-South & 86 & 12.3 \\
\hline Austral-South & 77 & 11.0 \\
\hline
\end{tabular}

With regard to the products' labelling systems present in Chile that identify GM products in the market, most respondents declared that they are not adequate neither clear $(84.6 \%)$, only $2.6 \%$ believe they are adequate and clear, and $12.8 \%$ did not know.

Figure 2 shows the responses before providing the definitions of transgenics and CRISPR. Over $60 \%$ of respondents declare that GM products can or may have adverse effects on health, and $65.2 \%$ declared there are ethical problems associated with the use of CRISPR in animals. When asked if they would agree to using CRISPR for improving animal health $43.6 \%$ said yes and $23.8 \%$ maybe. Agreement in using CRISPR for improving human health was lower (39.7\% yes; $22.6 \%$ maybe).

A significant effect of gender on agreeing on the of use genome editing (CRISPR) in humans $(P=0.033)$ and in animals $(P=0.001)$ and on the perception of a negative effect of GM products on human health $(P=0.002)$ was found, with women having a lower agreement and more negative perception (table 2). No effects were found for type of diet and education level.

Significant correlations were found between age and perceiving there are ethical problems with the use of CRISPR $(P=0.005, \mathrm{r}=0.11)$ and between age and the use of transgenic products $(P=0.04, \mathrm{r}=0.08)$. Also, a significant correlation was found between those respondents perceiving ethical problems with the use of genome editing and those that perceived an ethical problem with the use of transgenic products $(P<0.001, \mathrm{r}=0.52)$.

\section{PERCEPTIONS AFTER DELIVERY OF BIOTECHNOLOGIES DEFINITIONS}

After providing respondents with the definition of genome editing (CRISPR) and transgenic, they were asked how close these definitions were to their previous

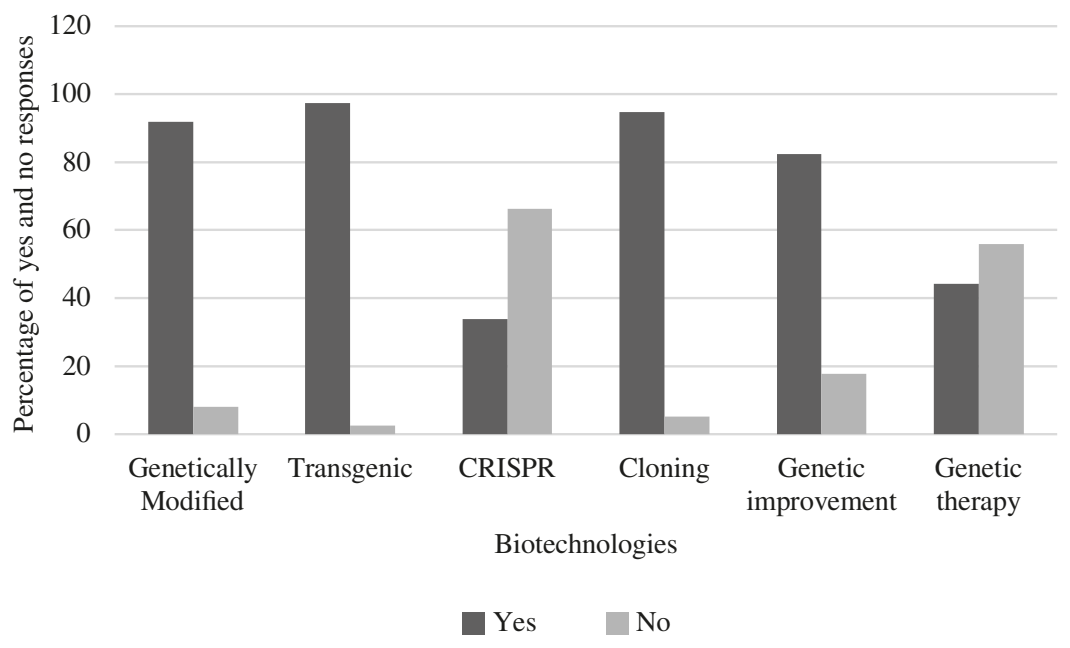

Figure 1. Distribution of respondents ( $\mathrm{n}=702$ ) according to if they had (yes) or not (no) heard previously the concepts Genetically modified, Transgenic, CRISPR, Cloning, Genetic improvement and Genetic therapy. 

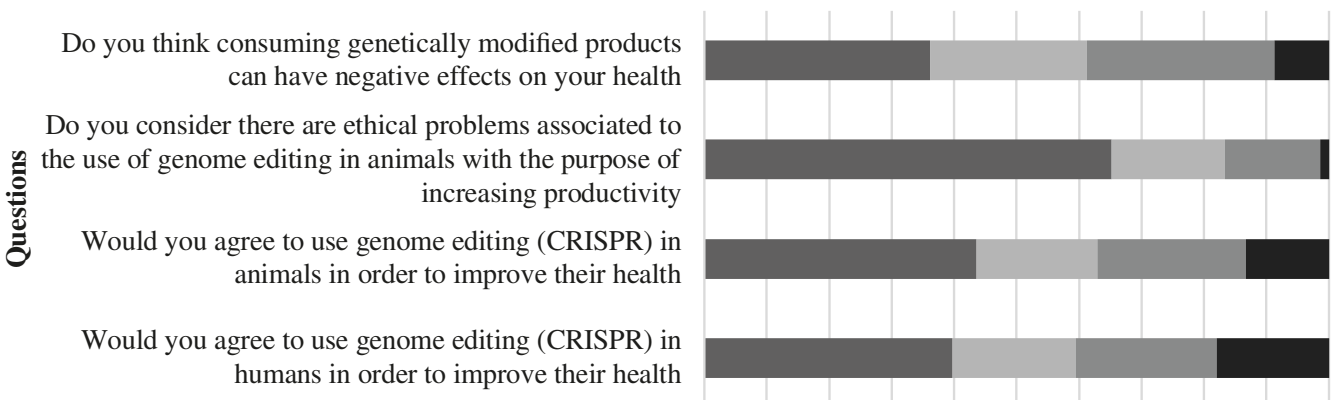

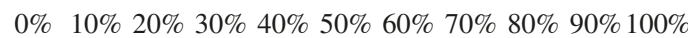

Percentage of Yes, No, Maybe and I don't know responses

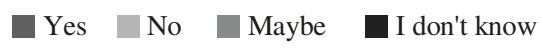

Figure 2. Distribution of respondents in percentages according to their responses (yes, no, maybe and do not know) to each question related to the use of genome editing, before providing them with the definition of genome editing.

Table 2. Results of the GLM ( $F$ value and P-value) for determination of the effect of gender, diet and education on responses to each question.

\begin{tabular}{|c|c|c|c|c|c|c|}
\hline \multirow{2}{*}{ Questions } & \multicolumn{2}{|c|}{ Gender } & \multicolumn{2}{|c|}{ Diet } & \multicolumn{2}{|c|}{ Education } \\
\hline & $\mathrm{F}$ & $\mathrm{P}$ & $\mathrm{F}$ & $\mathrm{P}$ & $\mathrm{F}$ & $\mathrm{P}$ \\
\hline $\begin{array}{l}\text { 1. Would you agree to use genome editing (CRISPR) in humans to } \\
\text { improve their health. }\end{array}$ & 3.43 & 0.033 & 0.24 & 0.787 & 0.14 & 0.872 \\
\hline $\begin{array}{l}\text { 2. Would you agree to use genome editing (CRISPR) in animals to } \\
\text { improve their health. }\end{array}$ & 0.762 & 0.001 & 0.27 & 0.762 & 0.18 & 0.839 \\
\hline $\begin{array}{l}\text { 3. Do you think consuming genetically modified products can have } \\
\text { negative effects on health. }\end{array}$ & 6.29 & 0.002 & 1.34 & 0.263 & 0.99 & 0.373 \\
\hline
\end{tabular}

own concepts of genome editing and transgenic. At five points Likert scale was used, where 1 corresponded to not similar at all and 5 was completely the same. Regarding CRISPR, 25.6\% said it was the same definition (5) they had before to the questionnaire and $12.3 \%$ said it was completely different to what they thought firstly (1); while $11.1 \%$ gave a score of 2 points, $27.2 \%$ scored it with 3 points and $23.8 \%$ scored the similarity with 4 points. For the definition of transgenic $45.44 \%$ said it was the same definition (5) and $1.71 \%$ said it was completely different; while $1.99 \%$ scored it with 2 points, $14.81 \%$ with 3 points and $36.04 \%$ scored the similarity with 4 points.

When asked about the willingness to eat genome edited food products (figure 3 ), more people were willing to eat vegetables developed through this biotechnology (43.2\% corn and $39.2 \%$ soybean) than animal products ( $25.4 \%$ salmon and $24.8 \%$ beef). The same tendency was observed for transgenic food products, with people being more willing to accept this biotechnology in the case of vegetables ( $50.3 \%$ corn and $46.3 \%$ soybean) than for animal products ( $26.8 \%$ salmon and $24.9 \%$ beef).

To understand their attitudes, respondents were asked to put themselves in the following situation; if genome editing allows providing salmons with resistance to disease or to certain pathogens, would you agree to use it? Overall, $39 \%$ agreed, $32.9 \%$ did not agree, $5.7 \%$ said maybe and $22.4 \%$ did not know. Afterwards, those that responded "yes" or "maybe" $(\mathrm{n}=431)$ were asked if they would be willing to consume this kind of salmon; $53.4 \%$ said they would be willing to consume it, $16.9 \%$ said they would not and $29.7 \%$ said they did not know if they would consume genome edited salmon.

After providing the definition of genome editing and transgenic, there were significant changes $(P<0.05)$ for both concepts when asking the question "do you think there are ethical problems associated with the use of genome editing (CRISPR)/transgenes in animals in order to increase productivity?". In the case of CRISPR, respondents that thought there was no ethical problem increased from $15.2 \%$ to $18.2 \%$, and those that said they did not know decreased from $29.8 \%$ to $1.4 \%(P=0.001)$. For transgenic food products, there was an increase (44\% to $52 \%$ ) in respondents that perceived an ethical problem in the production of transgenic organisms, a decrease in those that did not perceive an ethical problem $(23.4 \%$ to $17.52 \%$ ) and those that thought that maybe there is an ethical problem $(27.6 \%$ to $1.99 \%)$, while those that did not know increased from $5 \%$ to $28.34 \%(P=0.02)$. 
When asked about how beneficial they considered the use of CRISPR for the production of vegetable or animalbased food products, in a 5 points Likert scale, $8 \%$ said it was not beneficial at all (1) and $21.4 \%$ said it was very beneficial (5); while $9.7 \%$ scored the benefit with 2 points, $34.8 \%$ with 3 points and $26.2 \%$ with 4 points. Finally, when asked to mention GM products available in the Chilean market the most frequent vegetable products mentioned were corn, soybean and tomato. Animal origin products such as chicken, salmon and beef were mentioned in a lower frequency (table 3).

Table 3. Most frequent words used when asked to mention GM food present in Chilean markets. Only those with a frequency over 10 are included in the table.

\begin{tabular}{cc}
\hline Frequency & Word (English) \\
\hline 144 & corn \\
123 & soybean \\
123 & tomato \\
84 & fruit \\
80 & seeds \\
64 & greens \\
40 & wheat \\
27 & chicken \\
21 & vegetables \\
17 & cereals \\
17 & salmon \\
15 & canola (rapeseed) \\
15 & meat \\
13 & bovines \\
\hline
\end{tabular}

\section{DISCUSSION}

Citizens attitudes and perceptions about the use of different GM biotechnologies applied in animal and vegetable origin products was assessed through a questionnaire. The electronic application of the questionnaire was preferred since it is less time consuming and expensive than face to face interviews (Heerwegh 2009). On the other hand, online questionnaires can decrease social desirability which tends to be higher during face-to-face interviews, especially considering that issues regarding genetic modifications tend to have an ethical component.

There was a balance between responses of women and men, with most respondents being between 18 and 40 years of age and with a technical or professional degree. These ages are within the generation $\mathrm{Z}, \mathrm{X}$ and millennials, and it can explain the higher number of responses from these groups since they are the ones that most use social media in Chile according to $\mathrm{CADEM}^{2}$. The same survey shows that Twitter, Facebook and Whatsapp are the most used apps for sharing opinions, possibility that surveys provide. Only $15 \%$ of respondents were either vegetarian or vegan, results that are in agreement with the national survey on lifestyles of Chileans conducted in 2018, where $18 \%$ of respondents were either vegetarian or vegan ${ }^{3}$.

To assess the current knowledge on terminologies associated with genetic biotechnologies, participants were asked if they had or not heard six different terms. The most acknowledged terms were transgenic and cloning with over $95 \%$ declaring that they had heard them. On the other hand, genome editing (CRISPR) was the least known term,

2 CADEM. 2019. El Chile que viene. Uso de redes sociales. Available at: https://www.cadem.cl/encuestas/el-chile-que-viene-uso-de-lasredes-sociales/

3 CADEM. 2018. CADEM 2018. El Chile que viene. Available at: https://www.cadem.cl/encuestas/el-chile-que-viene-abril-2018/

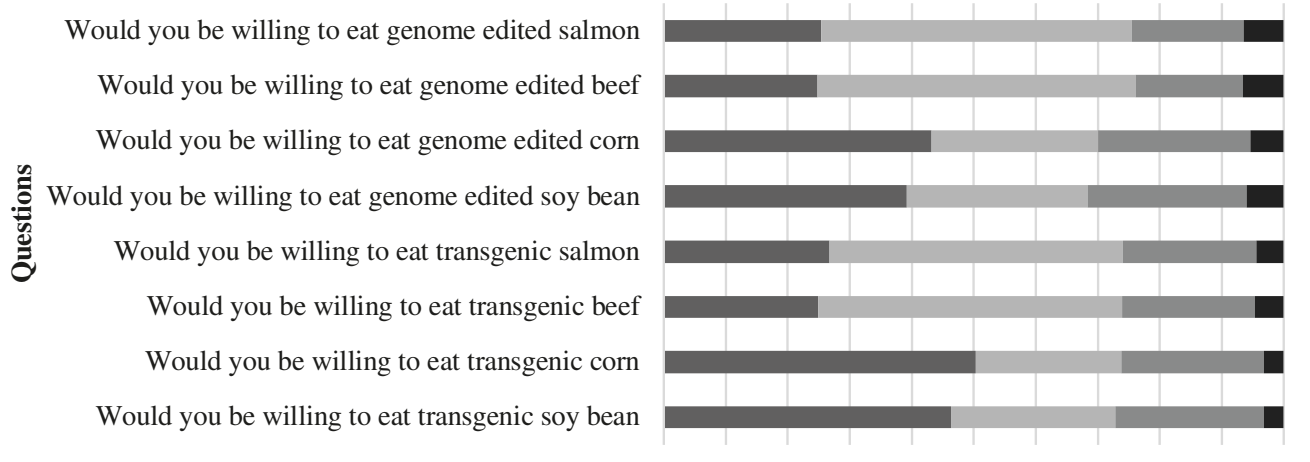

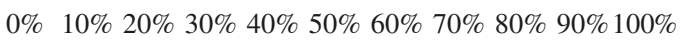

Percentage of Yes, No, Maybe and I don't know responses.

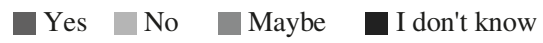

Figure 3. Responses given after reading the definition of genome editing (CRISPR) and transgenic about willingness to consume salmon, beef, corn and soybean subjected to these tools. 
similar to the findings of Uchiyama (Uchiyama et al 2018) where only $6.6 \%$ per cent of respondents, with no genetic disease, had heard this term. It is worth noticing that fewer people had heard the term genetically modified organism (GMO) than cloning and transgenic considering that the definition of GMO is "an organism, with the exception of human beings, in which the genetic material has been altered in a way that does not occur naturally by mating and/or natural recombination" (Bruetschy 2019) since both cloning and transgenic involve genetic modifications. This reflects the lack of information that citizens have in general about different labelling systems and their meaning. For example, Schnettler et al (2012) reported that $50 \%$ of consumers from the centre-south of Chile said they had received information related to GM products, but less than $20 \%$ were able to define it correctly.

All these biotechnologies raise many questions among the public, especially related to potential risks (i.e. is it safe?) and ethical concerns (i.e. who benefits from this technology?) (Bruetschy 2019), thus, information relative to them should be socialized through simple, clear and upstream communication processes (Wilsdon and Willis 2004). A study in Turkey reported that only $1 \%$ of respondents had never heard the term GMO, still they had little knowledge about this technology (Mürsel et al 2015). In the present study only $8 \%$ had never heard the term but being aware of the term does not necessarily imply a deep understanding of it.

When analyzing demographic characteristics and attitudes towards the use of these biotechnologies, women had a significant more negative attitude about the use of genome editing in humans and animals, and also considered that consuming GM products could have negative effects on health. Most literature on GMOs shows that women are more sceptical about the use of these products and their possible negative consequences on health (Moerbeek and Casimir 2005, Saher et al 2006, Heiman et al 2011). It also seems that women tend to think about the long-term risks of these biotechnologies while men focus on the short-term benefits (Moerbeek and Casimir 2005). With regard to diet type, contrary to our results (Saher et al 2006) found that meat eaters had a more positive view on GM products than meat avoiders. In the present study, no association was found between having a negative attitude towards consumption of GM products and type of diet.

Previous studies have found a relationship between higher education and greater knowledge about GMOs (Moerbeek and Casimir 2005, Saher et al 2006, Heiman et al 2011, López et al 2016). Popek and Halagarda (2017) also reported a lower level of knowledge regarding GMOs within citizens less educated, thus people with higher education, especially from the field of natural sciences could be more familiarised with the terms and understand better these biotechnologies. In the present study, no effect of education level was found, this could be because over $80 \%$ of respondents had completed a technical or professional degree and in some cases with postgraduate studies. Saher et al (2006) found that the leader predictor for attitudes towards GMOs was the field of study, with students from natural sciences having more positive attitudes. Still, the authors emphasise that multiple factors contribute and interact in GM attitudes (Saher et al 2006), this study did not include a question about the field of study. Nevertheless, Schnettler et al (2012) concluded that there is not a profile for consumers that approve or reject GM products.

Despite the low level of awareness of the term genome editing (CRISPR), $43.9 \%$ of respondents would be willing to use this technique for targeting animal health problems and $39.7 \%$ for human health. Similar results were described in Japan for its use in humans (Uchiyama et al 2018). Contrary to this, $65.2 \%$ of participants did consider there is an ethical problem when using this biotechnology for improving productivity. The present results are similar to previous studies where people were more supportive of using genome editing as a therapeutic tool than using it for improving certain traits (McCaughey et al 2016, Weisberg et al 2017).

After providing respondents the definition of genome editing (CRISPR) and transgenic, $25.6 \%$ and $45.44 \%$ of them said it was the same definition they had before the survey, respectively. Fewer respondents being aware of CRISPR can be explained because it is a newer biotechnology developed in 2013 (Doudna and Charpentier 2014) while transgenics were introduced in the 1980-90s (Zhang et al 2016). Despite the novelty of this technique, around $30 \%$ of respondents agreed that the definition of genome editing provided was the same they had.

Although this is the first Chilean report about the knowledge and perceptions about CRISPR, our results showed that Chilean respondents are more familiarised with its definition compared to Japanese participants, where $6 \%$ of respondents had heard the term (Uchiyama et al 2018). Conversely to previous reports in Chile, we found a higher number of respondents that knew the meaning of transgenic compared to the less than $30 \%$ reported by (Schnettler et al 2012, 2016). This difference might be explained by the higher education level of respondents from the present study, while in Schnettler et al (2012, 2016) most respondents had not completed a technical or professional degree, and half of the sample were students.

When analysing the willingness to eat GM food, the type of organism (plant or animal) is relevant for public opinion (Kronberger et al 2014). This has been observed with US participants in which plant-to-plant gene combination received more support than to animal-plant combination (Frewer et al 2004). Indeed, in a study about societal aspects of genetically modified foods, it is suggested that plant and microorganism genetic modifications are more accepted compared to those in animals (Frewer et al 2004). This could explain our result, where more people were willing to eat vegetables than animal products subjected to transgenic or gene editing methods. It must be highlighted that although 
numerous recent studies have described the potential uses of CRISPR in animal and crop production, there is scarce information on the public acceptance of this technique. In this regard, a multi-country and massive survey found that in the USA, Canada, Belgium, France, and Australia, $56,47,46,30$, and $51 \%$ of respondents, respectively, were willing to consume both GM and CRISPR food (Shew et al 2018). Considering the mentioned report, the present results fit very well with Australia and Belgium percentage of willingness. Our result reveals that both transgenic and CRISPR technology are perceived in a similar way, even though their definitions are quite different. A similar conclusion was obtained by Shew and collaborators on their global CRISPR versus GMO public acceptance and valuation study (Shew et al 2018).

It is well documented that the perceived benefits and risks of GM shift the public attitudes towards genetic manipulation. For example, a majority of respondents accept genetic changes with the purpose of improving animal health and welfare, but when related to genetic disease in humans this receptivity decreases (Robillard et al 2014). In this study, the hypothetical situation if genome editing allows providing salmons resistance to disease or certain pathogens, would you agree to use it? a total of $39 \%$ of respondents agreed (yes and maybe), similar results were obtained for cattle genetically modified perception in the USA (McConnachie et al 2019). However, followed by the question would you be willing to consume these salmon? only half of this group agreed. This trade-off attitude in the Chilean respondents reflects the conflict and the thinking process to which they were faced. Even in the "positive perception toward genetic modification sub-group" we constated that a big proportion of them are not willing to eat this food. When looking into the detail of these respondents, vegan people were not represented in this sub-sampling, but among people willing to consume genome editing salmon a big proportion were men averaging 41 years of age, with college and postgraduate education levels.

It is interesting to note that the most frequent responses obtained regarding which GM product people knew were corn, soybean and tomato. These products are in line with the GM seed production in Chile where maize, canola and soybean have been the main products for export (Sánchez and León 2016); while cotton, table grapes and tomato represent less than $1 \%$ of the total area of GM seed (Sánchez and León 2016) present in the country. For this reason, it calls our attention the high frequency of tomato in this study. This misconception about GM tomato produced in Chile is assumed perhaps on the prolonged breeding technologies applied, where researchers are creating new traits and varieties of tomatoes worldwide. We must point out, that there is no GM crop production for food, human consumption or seed, for the domestic market in Chile. Therefore, the presence of fruit, seeds, greens, wheat, vegetables, cereals and canola (rapeseed) on the list represents a lack of knowledge about the regulatory framework by Chilean citizens. In this regard, Salazar et al (2019) concluded that the restricted commercial use to seed-export has made Chile a seed nursery to GM products. On the other hand, in this study some animal species were identified including chicken, salmon and beef. Despite the lower frequency of appearance, again the wrong idea that GM products of animal origin make it into the Chilean market is present. To date, salmon is the first genetically engineered EG animal approved for human consumption, but only in the United States and Canadian markets ${ }^{4}$ (FDA 2015).

In conclusion, this study shows that among Chilean citizens there is a high awareness of concepts such as transgenic, cloning and genetically modified, and low awareness of the CRISPR and genetic therapy concepts. Most respondents perceived possible negative effects on health regarding the consumption of GM products, with women having a significantly more negative attitude towards them. Still, a high willingness to use CRISPR for improving animal and human health was reported. When comparing vegetable and animal products that underwent CRISPR or transgenes, the willingness to consume these products is higher for vegetables than for animal origin products. Finally, education through the provision of clear information seems to be essential. For example, in the present study perception was significantly changed after providing the definition of CRISPR and transgenes concepts.

\section{ACKNOWLEDGEMENTS}

The authors would like to acknowledge all participants that took the time to respond the questionnaire. Additionally, to Dr. Gabriel Leon. This study was funded by the Agencia Nacional de Desarrollo e Investigación (ANID) from Chile through project FONDECYT N 11190649.

\section{CONFLICTS OF INTEREST}

The authors declare no conflict of interest neither with persons or institutions.

\section{ETHICAL STATEMENT}

The ethical approval (Protocol code 190403005) provided by Pontificia Universidad Católica for Project FONDECYT N 11190649

\section{REFERENCES}

Bartkowski B, Theesfeld I, Pirscher F, Timaeus J. 2018. Snipping around for food: Economic, ethical and policy implications of CRISPR/Cas genome editing. Geoforum 96, 172-180.

Bruetschy C. 2019. The EU regulatory framework on genetically modified organisms (GMOs). Transgenic Res 28, 169-174.

4 FDA. 2015. AquAdvantage Salmon Approval Letter and Appendix. Available at: https://www.fda.gov/animal-veterinary/animals-intentional-genomic-alterations/aquadvantage-salmon. 
Crispo M, Mulet AP, Tesson L, Barrera N, Cuadro F, et al. 2015. Efficient generation of myostatin knock-out sheep using CRISPR/Cas9 technology and microinjection into zygotes. PLOS ONE 10, e0136690.

Cui K, Shoemaker SP. 2018. Public perception of genetically-modified (GM) food: A nationwide Chinese consumer study. Npj Sci Food 2, 1-8.

Dong OX, Ronald PC. 2019. Genetic engineering for disease resistance in plants: Recent progress and future perspectives. Plant Physiol 180, 26-38.

Doudna JA, Charpentier E. 2014. The new frontier of genome engineering with CRISPR-Cas9. Science. 346, 1258096.

Frewer L, Lassen J, Kettlitz B, Scholderer J, Beekman V, et al. 2004. Societal aspects of genetically modified foods. Food Chem Toxicol 42, 1181-1193.

Gao Y, Wu H, Wang Y, Liu X, Chen L, et al. 2017. Single Cas9 nickase induced generation of NRAMP1 knockin cattle with reduced offtarget effects. Genome Biol 18, 1-15.

Hai T, Teng F, Guo R, Li W, Zhou Q. 2014. One-step generation of knockout pigs by zygote injection of CRISPR/Cas system. Cell Res 24, 372-375.

Hanssen L, Dijkstra AM, Sleenhoff S, Frewer LJ, Gutteling JM. 2018. Revisiting public debate on genetic modification and genetically modified organisms. Explanations for contemporary Dutch public attitudes. J Sci Commun 17, 1-20.

Heerwegh D. 2009. Mode differences between face-to-face and web surveys: an experimental investigation of data quality and social desirability effects. Int J Public Opin Res 21, 111-121.

Heiman A, Agmon O, Fleisher R, Zilberman D. 2011. Attitude and purchasing decisions regarding genetically modified foods based on gender and education. Int J Biotechnol 12, 50-65.

Jacobs TB, La Fayette PR, Schmitz RJ, Parrot WA. 2015. Targeted genome modifications in soybean with CRISPR/Cas9. BMC Biotechnol 15, 1-10.

Kawano Y, Honda A. 2017. Gene targeting in rabbits: single-step generation of knock-out rabbits by microinjection of CRISPR/Cas9 plasmids. Methods Mol Biol 1630, 109-120.

Kronberger N, Wagner W, Nagata M. 2014. How natural is "more natural"? the role of method, type of transfer, and familiarity for public perceptions of cisgenic and transgenic modification. Sci Commun 36, 106-130.

Li M, Dai S, Liu X, Xiao H, Wang D. 2021. A detailed procedure for CRISPR/Cas9-mediated gene editing in tilapia. Hydrobiologia 848, 3865-3881.

Li ZS, Liu ZB, Xing AQ, Moon BP, JP, Koellhoffer, et al. 2015. Cas9guide RNA directed genome editing in soybean. Plant Physiol 169, 960-970.

López OAM, Pérez EF, Fuentes EES, Luna-Espinoza I, Cuevas FA. 2016. Perceptions and attitudes of the Mexican urban population towards genetically modified organisms. Br Food J 118, 2873-2892.

McCaughey T, Sanfilippo PG, Gooden GEC, Budden DM, Fan L, et al. 2016. A global social media survey of attitudes to human genome editing. Cell Stem Cell 18, 569-572.

McConnachie E, Hötzel MJ, Robbins JA, Shriver A, Weary DM, et al. 2019. Public attitudes towards genetically modified polled cattle. PLoS One 14, 1-15.

McFarlane GR, Salvesen, HA, Sternberg A, Lillico SG. 2019. On-farm livestock genome editing using cutting edge reproductive technologies. Front Sustain Food Syst 3, 1-7.

Menchaca, A. 2021. Sustainable food production: The contribution of genome editing in livestock. Sustainability 13, 6788.

Moerbeek H, Casimir G. 2005. Gender differences in consumers' acceptance of genetically modified foods. Int J Consum Stud 29, 308-318
Mürsel T, Melek B, Alev Y, Nese SY. 2015. Consumer awareness, perception and attitudes towards genetically modified foods in Turkey. Br Food J 117, 1426-1439.

Ni W, Qiao J, Hu S, Zhao X, Regouski M, et al. 2014. Efficient gene knockout in goats using CRISPR/Cas9 system. PLOS ONE 9.

Pickens J. 2005. Attitudes and perceptions. In: Borkowski N (ed). Organizational Behavior in Health Care. Jones and Bartlett Publishers, Sudbury, USA. 43-75.

Popek S, Halagarda M. 2017. Genetically modified foods: Consumer awareness, opinions and attitudes in selected EU countries. Int $J$ Consum Stud 41, 325-332.

Ritter C, Shriver A, McConnachie E, Robbins J, von Keyserlingk MAG, et al. 2019. Public attitudes toward genetic modification in dairy cattle. PLoS One 14, 1-15.

Robillard JM, Roskams-Edris D, Kuzeljevic B, Illes J. 2014. Prevailing public perceptions of the ethics of gene therapy. Hum Gene Ther 25, $740-746$.

Saher M, Lindeman M, Hursti UKK. 2006. Attitudes towards genetically modified and organic foods. Appetite 46, 324-331.

Salazar MP, Valenzuela D, Tironi M, Gutiérrez RA. 2019. The ambivalent regulator: the construction of a regulatory style for genetically modified crops in Chile. Tapuya Lat Am Sci Technol Soc 2, 199-219.

Sánchez MA, León G. 2016. Status of market, regulation and research of genetically modified crops in Chile. N Biotechnol 33, 815-823.

Schnettler B, Sepúlveda B, Ruiz D. 2008. Acceptance of transgenic milk in La Araucania Region,Chile. Chilean J Agric Res 68, 380-390.

Schnettler B, Miranda H, Sepúlveda J, Denegri M. 2012. Preferências dos consumidores aos alimentos geneticamente modificados de origem animal e vegetal no Chile. Cienc Tecnol Aliment 32, 15-25.

Schnettler B, Velásquez C, Lobos G, Orellana L, Sepúlveda J, et al. 2016. Acceptance of beef obtained through genetic modification and cloning in university students and working adults in southern Chile. Rev Fac Ciencias Agrar 48, 141-159.

Shew AM, Nalley LL, Snell HA, Nayga RM, Dixon BL. 2018. CRISPR versus GMOs: Public acceptance and valuation. Glob Food Sec 19, 71-80.

Svitashev S, Schwartz C, Lenderts B, Young JK, Mark A. 2016. Genome editing in maize directed by CRISPR-Cas9 ribonucleoprotein complexes. Nat Commun 7, 13274.

Tait J. 2001. More faust than Frankenstein: The European debate about the precautionary principle and risk regulation for genetically modified crops. J Risk Res 4, 175-189.

Uchiyama M, Nagai A, Muto K. 2018. Survey on the perception of germline genome editing among the general public in Japan. J Hum Genet 63, 745-748.

Véron N, Qu Z, Kipen PAS, Hirst CE, Marcelle C. 2015. CRISPR mediated somatic cell genome engineering in the chicken. Dev Biol 407, 68-74.

Weisberg S, Badgio D, Chatterjee A. 2017. A CRISPR New world: Attitudes in the public towards innovations in human genetic modification. Front Public Health 5, 117.

Whitworth KM, Lee K, Benne JA, Beaton BP, Spate LD, et al. 2014. Use of the CRISPR/Cas9 system to produce genetically engineered pigs from in vitro-derived oocytes and embryos. Biol Reprod 91, 78-79.

Wilsdon J, Willis R. 2004. See-through Science. Why public engagement needs to move upstream. HenDI Systems, London, UK.

Woo JW, Kim J, Kwon SI, Corvalán C, Cho SW, et al. 2015. DNAfree genome editing in plants with preassembled CRISPR-Cas9 ribonucleoproteins. Nat Biotechnol 33, 1162-1164.

Zhang C, Wohlhueter R, Zhang H. 2016. Genetically modified foods: A critical review of their promise and problems. Food Sci Hum Wellness 5, 116-123. 